\title{
Comparative risk assessment for new cow-level Mycobacterium avium ssp. paratuberculosis infections between 3 dairy production types: Organic, conventional, and conventional-grazing systems
}

\author{
A. Beaver, ${ }^{*} \dagger^{1}$ P. L. Ruegg, $\ddagger$ Y. T. Gröhn, $\dagger$ and Y. H. Schukken $† \S$ \\ *Department of Animal Science, and \\ †Department of Population Medicine and Diagnostic Sciences, College of Veterinary Medicine, Cornell University, Ithaca, NY 14853 \\ ‡Department of Dairy Science, University of Wisconsin, Madison 53706 \\ $\S$ GD Animal Health Service, 7400 AA Deventer, the Netherlands
}

\section{ABSTRACT}

Johne's disease, a granulomatous enteritis of ruminant animals, is a hidden threat on dairy farms, adversely affecting animal welfare as well as herd productivity. Control programs in the United States advocate for specific management practices to temper the spread of the causal organism (Mycobacterium avium ssp. paratuberculosis, MAP), such as improving calving area hygiene and limiting introduction of replacement stock with unknown infection status. A need remains for direct exploration of Johne's disease prevention strategies in the United States with respect to production type. Alongside the growing demand for organic products, the safety of organic dairy practices with respect to MAP control is warranted. Further, conventional herds for which organic practices such as pasture grazing are used should be situated within the risk spectrum. We developed a risk assessment model using the US Voluntary Bovine Johne's Disease Control Program as a framework, with the goal of evaluating the risk of new cow-level MAP infections. A total of 292 organic and conventional farms in 3 states were surveyed on management practices, and an overall analysis was conducted in which each farm was first scored on individual practices using a range of "no risk" to "high risk," according to the literature. The sum of all risk factors was then analyzed to quantify and compare the risk burden for each production type. Organic herds received higher overall risk scores compared with both conventional grazing and nongrazing subtypes. To identify which factors contributed to the overall increased risk for organic herds, the management practices were categorized and evaluated by logistic regression. We

\footnotetext{
Received April 25, 2016.

Accepted August 12, 2016.

${ }^{1}$ Corresponding author: ab2368@cornell.edu
}

determined that the increased risk incurred by organic herds was predominantly due to decisions made in the calving area and preweaned calf group. However, although certain individual risk factors related to calf management are commonly involved in prevention strategies (e.g., cow/calf separation) and were thus included in the overall risk assessment, empirical evidence linking them to the spread of MAP is lacking. Instead, these factors are problematic when executed with other management decisions, leading to a hypothesized synergism of transmission risk. To this end, we developed a set of compound risk factors, which were also evaluated as outcomes in logistic regression models, with production type serving as the predictor of interest. Organic farms in our study were more susceptible to risks associated with the synergism of study variables. Notably, organic producers were most likely to allow calves to spend extended time with the dam, while also lacking a dedicated calving area. Additionally, calves in organic herds were more often permitted to nurse even with poor udder hygiene on farm. A heightened vigilance toward calving area hygiene is therefore indicated for these herds.

Key words: Johne's disease, organic management, conventional management, production type

\section{INTRODUCTION}

\section{Johne's Disease: Cause, Implications, and Management Initiatives}

Johne's disease, which primarily affects cattle and other ruminant species, is a chronic infection of the gastrointestinal tract caused by the bacterium Mycobacterium avium ssp. paratuberculosis (MAP). Calves under 6 mo are most susceptible to MAP infection (Lombard, 2011). The disease is characterized by a prolonged incubation period (typically 1-6 yr) before the onset of clinical signs, during which infected, yet asymptom- 
atic animals may shed MAP bacteria into manure and milk. Initial signs, such as decreased milk production, low fertility, reduced body condition, or roughening of the hair coat, may be subtle, and animals are often culled from dairy herds before the occurrence of clinical disease. Clinical signs are progressive and typically manifest as weight loss and diarrhea, eventually leading to severe dehydration and cachexia (Whitlock and Buergelt, 1996; Manning and Collins, 2001).

The primary means of MAP transmission is the fecal-oral route. In particular, calf contact with manure from adult cows presents an unparalleled risk for vertical MAP transmission (Doré et al., 2012). MAP shed into manure may lead to environmental contamination and subsequent contamination of teats and udders; the milk or colostrum of uninfected animals may thus become adulterated. MAP may also be shed directly into the milk and colostrum of infected animals (Sweeney et al., 1992). Unpasteurized sources of milk present a risk to calves, yet MAP has also been shown to survive pasteurization at initial concentrations exceeding $10^{4}$ cells/L (Grant et al., 2005). Intrauterine transmission is also possible, although it does not appear to play a major role in the spread of MAP (Mortensen et al., 2004).

The presence of MAP may be detected in serum, milk, or fecal samples from individual animals via ELISA (detection of MAP antibodies), PCR, or culture methods (detection of the casual organism) (Wilson et al., 2010). More recently, ELISA and PCR techniques have been applied to bulk tank milk to evaluate MAP presence and prevalence at the herd level (van Weering et al., 2007; Slana et al., 2009; Cazer et al., 2013; Beaver et al., 2016). The dairy industry suffers substantial economic losses due to MAP, based on factors such as increase in overall cull rate and replacement costs, decreased revenue from lower milk production, and increased veterinary expenses. Ott et al. (1999) estimated that lost productivity as a result of Johne's disease is responsible for an annual 200 to 250 million dollar loss for the US dairy industry. From a human health standpoint, on-farm risk mitigation is also a valuable initiative because MAP has been implicated as a potential cause of human Crohn's disease (see Feller et al., 2007). In the United States, dairy producers may choose to participate in the Voluntary Bovine Johne's Disease Control Program (VBJDCP). The program focuses on controlling the spread of MAP between and within herds, and it has been in effect since 1999. A crucial part of the VBJDCP is identifying and implementing preventative strategies focused on calf management, curtailing environmental contamination, and restricting introduction of potentially infected animals into the herd.

\section{The Relationship Between Johne's Disease Risk Factors and Production Type}

Key research has been conducted to address differences between organic and conventional farming, but the focus has typically been on economic and environmental consequences (Pieper et al., 2014). However, several studies have dealt with management implications related to disease prevention. Stiglbauer et al. (2013) compared management on organic and conventional farms and concluded that organic farms used outside resources (such as nutritionists and veterinarians) less often and also administered vaccinations less often. Richert et al. (2013) investigated perceptions and definitions of mastitis, ketosis, and pneumonia between conventional and organic herds, in addition to rate of recorded cases. Disease perceptions were largely similar between the production types and clearly influenced the rate of farmer-identified cases.

The safety of organic practices with respect to Johne's disease merits extensive evaluation, particularly in light of the dramatic increase in consumer demand for organic products over the last decade (Organic Trade Association, 2016). Few studies have sought to compare management practices of organic and conventional farm types in a risk-assessment type analysis. According to Zwald et al. (2004), conventional farms were more likely to report positive a Johne's diagnosis in their herds ( $48.5 \%$ compared with $25 \%$ of organic farms). However, the basis of these diagnoses is not described further, and the herd sizes of the conventional farms tended to be larger. Pieper et al. (2014) reviewed requirements for organic farming in Canada and developed a conceptual analysis regarding the effect of these practices on Johne's disease transmission. The authors acknowledged the necessity for empirical research, not only with regard to organic farms, but also for conventional farms implementing relevant organic practices.

In the present large-scale study of 292 farms, we review the management practices from 3 types of US dairy production systems in light of the risk of new cow-level MAP infections. The production types considered are organic (ORG), conventional nongrazing (CON-NG), and conventional grazing (CON-GR). This study is the first to evaluate Johne's risk factors with respect to production type and grazing on US dairy farms, and the study design included herd-size matching and location matching from 3 regions of the United States. 


\section{MATERIALS AND METHODS}

\section{Questionnaire}

The questionnaire results were obtained from a multi-institutional study of 292 organic and conventional farms from 3 states of the United States: Oregon, New York, and Wisconsin. Herd recruitment has been described previously (Bergman et al., 2014; Stiglbauer et al., 2013; Cicconi-Hogan et al., 2013; Richert et al., 2013). In summary, farms with $\geq 20$ cows having sold milk commercially for $\geq 2$ yr were eligible for inclusion. To be classified as having an organic herd, farms must have shipped certified organic milk for $\geq 2$ yr before study enrollment. Conventional herds were sizematched to organic herds based upon the total number of lactating and dry cows, divided into 4 categories $(<100,100-199,200-299$, and $\geq 300)$. The number of conventional herds in each state was selected based on organic-to-conventional state ratios. In total, 97 farms were selected from New York, 48 from Oregon, and 147 from Wisconsin, with organic-to-conventional ratios of $3: 1,1: 1$, and $2: 1$, respectively. For the analysis, conventional farms were divided into nongrazing (CON-NG, $\mathrm{n}$ $=64)$ and grazing $(\mathrm{CON}-\mathrm{GR}, \mathrm{n}=36)$ for comparison with organic (ORG, $\mathrm{n}=192)$ farms; CON-GR herds were defined as those with at least $1 \mathrm{mo} / \mathrm{yr}$ of daily access to a pasture providing $\geq 30 \%$ of DMI.

The questionnaire has been described in detail by Richert et al. (2013) and is available online at http:// milkquality.wisc.edu/organic-dairies/project-c-o-w/. A herd visit was conducted at each farm, and questionnaires were administered at the time of the visit. The questions concerned implementation of on-farm management procedures and included several direct questions relating to Johne's disease status, Johne's testing, and Johne's management protocols. Additionally, during these herd visits, udder hygiene was scored on each farm (for all animals in herds with $\leq 50$ cows, and for a representative sample of $20 \%$ of cows for larger herds) using a scoring system outlined by Schreiner and Ruegg (2003).

\section{Variable Selection}

Variables from the questionnaire were selected based upon potential association with MAP prevalence and organized according to the nature of the risk, using the handbook for the VBJDCP as a framework. The management practices in our study were divided into 2 major categories: within-herd transmission risk and introduction risk. Within-herd transmission was further partitioned into the subcategories calving area, preweaned calf group, and postweaned heifer group. Introduction risk was defined based upon categories of additions and replacement stock.

As outlined in the VBJDCP manual, the risk in the calving area is assessed based upon the potential for neonatal calves to ingest manure from mature cows. We categorized the type of calving area on each farm according to several parameters, including whether a dedicated calving area was used, and if not, whether sick animals or other lactating cows were permitted in the area. For calves nursing the dam, time spent in the calving area was recorded and categorized into 3 time frames: immediate removal, removal between 1 and 6 $\mathrm{h}$ of contact, and removal after $\geq 6 \mathrm{~h}$ of contact. The source of the colostrum was classified as fresh or stored, and as single source or pooled. Finally, several hygiene precautions taken in the periparturient period were considered: checking fresh cows for dirt, udder clipping, and footbaths for both dry and fresh cows.

The risk for preweaned calves was also assessed based upon the potential for this group to ingest MAPcontaminated manure from adult cows. Producers were asked about their milk feeding practices (e.g., whether whole milk was fed, and whether the source was pasteurized). Although not included in the VBJDCP manual, the housing of preweaned calves was incorporated into our risk assessment because calves may begin shedding MAP in a short time period following infection (van Roermund et al., 2007; Mortier et al., 2014). We also considered the presence of calf scours and treatment protocols for scours cases. For postweaned heifers, we focused primarily on pasture movements (for ORG and CON-GR systems), manure spreading, loader management, and primary water sources. Regarding the introduction risk, all categories of additions and replacement animals were considered: preweaned and weaned heifers, dairy cows, bulls, and other livestock. Additionally, sourcing these animals from multiple different farms was considered a risk factor.

As an auxiliary point of interest, we evaluated variables directly related to Johne's disease testing and management of known MAP-positive animals. Variables directly related to Johne's disease testing were not included in the main analysis because of a hypothesized increased likelihood that farms with MAPpositive animals would conduct testing and participate in control programs. Further, the primary goal of the study was to evaluate the risk of new cow-level MAP infections. Lack of diagnostic testing cannot accurately be described as a transmission risk, and some level of self-prediction is inherent in using test results to predict new MAP infections. However, these statistics are reported because they provide valuable supplementary 
information and have not previously been compared between US production types.

Variables representing "compound risks" were generated by combining and dichotomizing the results from 2 risk factor variables if they were hypothesized to have a synergistic effect on the level of risk. Compound risks were assessed within and between the risk factor categories (e.g., calving area management and additions/ replacement group). A summary of risk combinations follows. Farms permitting calves to nurse or allowing extended cow-calf contact $(\geq 6 \mathrm{~h})$ were evaluated for an inclination to simultaneously conduct any of the following procedures: lacking a dedicated calving area, permitting sick or lactating cows in the calving area, failing to provide footbaths or clip udders of periparturient cows, having a poor average udder hygiene $(>2.5)$, failing to check fresh cows for dirt, and keeping animals positive for Johne's disease until after calving. Several additional biologically relevant combinations of these variables were also evaluated, such as lack of footbaths and lack of a dedicated calving area.

Herds for which group calf housing was permitted were similarly evaluated for a propensity to allow new preweaned calves into the herd and for the presence of treated or untreated scours. Farms allowing new dairy animals into the herd were assessed for lack of a dedicated calving area or presence of lactating or sick cows in the area, pasture sharing between heifers and cows, spreading manure, and feeding of whole milk or waste milk to calves. The milk feeding was also evaluated alongside the bulk tank testing variable. Finally, the combination of surface water use and shared pasture between heifers and cows was tested.

\section{Statistical Analyses}

An overall risk assessment was conducted as follows: for each farm, key risk factors were individually scored on a scale of 1 to 3 , with 1 representing low risk, 2 representing moderate risk, and 3 representing high risk. The number assignments for the risk factors and the rationale for the scoring decisions are provided in Table 1. The risk scores for these variables were then tallied for each farm. A one-way ANOVA was conducted to evaluate the distribution of risk scores for the 3 farm types (ORG, CON-NG, and CON-GR). The omnibus test was followed up with Tukey honestly significant difference (HSD) post hoc comparisons. Additionally, ANOVA and Tukey HSD tests were conducted on each separate risk category.

To gain a more nuanced understanding of the results of the overall risk assessment, each individual risk factor was modeled as the outcome in a logistic regression, with production type (CON-NG, CON-GR, and ORG) as the predictor of interest. Due to the importance of herd size and state in the study design, these variables were included as additional predictors in all models. The herd size variable was represented as categorical $(<100,100-200,>200)$. The general form of the logistic model may be expressed as

$$
\begin{aligned}
\ln \left(\frac{Y}{1-Y}\right)= & \alpha+\beta_{1} \text { Production }_{\mathrm{ORG}}+\beta_{2} \text { Production }_{\mathrm{CON}-\mathrm{GR}} \\
& +\beta_{3}{\text { Herd } \text { Size }_{100-200}+\beta_{4} \text { Herd Size }_{>200}} \\
& +\beta_{5} \text { State }_{\mathrm{NY}}+\beta_{6} \text { State }_{\mathrm{OR}}
\end{aligned}
$$

where $\ln \left(\frac{Y}{1-Y}\right)$ represents the natural $\log$ of the odds for a given outcome variable, $\alpha$ is the intercept, and $\beta_{1}$ through $\beta_{6}$ represent the parameter estimates for the included predictors. Specifically, $\beta_{1}$ and $\beta_{2}$ are the slope estimates for the variable production type, with $\mathrm{CON}-$ NG serving as the reference level; $\beta_{3}$ and $\beta_{4}$ are the estimates for herd size, with a herd size of $<100$ as the reference level, and $\beta_{5}$ and $\beta_{5}$ are the estimates for state, with Wisconsin as the reference level. As with the individual risk factors, the compound risks were modeled as outcomes in logistic regressions with production type, herd size, and state as predictor variables. If necessary, Firth's bias correction was employed for models that did not produce a reliable maximum likelihood estimate due to quasi-separation of data. Tukey HSD adjustments were made for the odds ratio comparisons. All statistical analyses were carried out using SAS (version 9.4, SAS Institute Inc., Cary, NC), and the figures were generated using GraphPad Prism (version 6, GraphPad, La Jolla, CA).

\section{RESULTS}

\section{Overall Risk Assessment}

Risk scores for all farms ranged from 5 to 26 , with a mean $\pm \mathrm{SD}$ of $15.04 \pm 4.13$. The ANOVA yielded a significant result $\left(F_{2,289}=14.60, P<0.0001\right)$. Specifically, Tukey HSD comparisons revealed differences in the mean risk scores between ORG and CON-GR herds $(P=0.019)$ and between ORG and CON-NG herds $(P$ $<0.0001)$, with the higher score means and thus higher risks attributed to ORG herds. The variable nursing was not included in the overall risk assessment because of the implicit overlap with "calves remain with the dam." However, in an effort to observe whether inclusion of nursing would alter results, a separate risk assessment was run with nursing as an additional low-risk factor. 
The $P$-value for the ORG and CON-GR comparison changed slightly $(P=0.016)$, but the import of all results remained the same.

No significant difference occurred in the risk scores between conventional subtypes. The results are presented graphically in Figure 1. When the overall risk assessment was subdivided into risk categories, ORG herds had higher mean risk scores than CON-NG and CON-GR herds in the calving area $(P=0.013$ and $P$ $=0.014$, respectively) and in the preweaned calf group $(P<0.001$ and $P=0.013$, respectively). Additionally, CON-GR herds had higher risk scores than CON-NG herds in the preweaned calf group $(P=0.033)$. Results are shown in Figure 2.

\section{Individual Risk Factors}

The results of the logistic regression analyses, in addition to descriptive statistics, are presented in Tables 2, 3 and 4. Significance levels for odds ratios (OR) reflect Tukey HSD adjustments.

Calving Area Management. More ORG farms allowed calves to nurse colostrum (40\%) compared with CON-NG farms $(9 \%, \mathrm{OR}=6.7, P=0.0001)$. Similarly, ORG herds were permitted extended contact $(\geq 6 \mathrm{~h})$ between cows and calves at an increased frequency compared with CON-NG herds $(\mathrm{OR}=8.9, P=0002)$. Although a higher percentage of ORG farms allowed nursing and extended contact compared with CON-GR farms, this difference was not significant after the adjustment for multiple comparisons.

With regard to calving area hygiene, CON-GR farms had a higher likelihood of clipping the udders of fresh cows after calving than did ORG farms (28 vs. $12 \%$, $\mathrm{OR}=3.5, P=0.036)$, and CON-NG farms had a 2.5 times higher likelihood $(P=0.044)$ of administering footbaths following calving (38\%) compared with ORG farms $(17 \%)$. No significant difference was found in the number of farms in each group providing dedicated calving areas, allowing sick animals or other lactating animals into the calving area, or provisioning stored colostrum to calves (from pooled or single sources).

Preweaned Calf Group. Waste milk was more routinely fed on ORG (71\%) and CON-GR farms (61\%) compared with CON-NG farms (36\%); the odds of provisioning waste milk to calves was 5.9 times higher for ORG herds $(P<0.0001)$ and 3.4 times higher for CONGR herds $(P=0.026)$. Similarly, ORG and CON-GR farms had a higher probability of feeding unpasteurized waste milk (61 and $58 \%$, respectively) compared with CON-NG systems: the likelihood was 3.1 times higher for CON-GR farms $(P=0.032)$ and 4.0 times higher for ORG farms $(P<0.0001)$. A larger percentage of ORG farms fed calves whole milk $(88 \%)$ vs. $64 \%$ of
CON-GR $(\mathrm{OR}=4.4, P=0.002)$ and $42 \%$ of $\mathrm{CON}-\mathrm{NG}$ herds $(\mathrm{OR}=9.1, P<0.0001)$. Finally, a larger percentage of ORG farms (82\%) fed unpasteurized whole milk to calves, in contrast with $61 \%$ of CON-GR $(\mathrm{OR}=$ $3.5, P=0.008)$ and $36 \%$ of CON-NG herds (OR $=7.0$, $P<0.0001)$. With respect to calf housing, preweaned calves were group-housed at a 3.8 times lower frequency on CON-GR farms (22\%) compared with ORG farms $(48 \%, P=0.005)$.

Postweaned Heifer Group. Manure spreading on pasture was significantly more common for grazing systems (48\% of ORG and $47 \%$ of CON-GR farms) compared with CON-NG farms (19\%), with 5.4 and 3.3 multiplicative increases in the odds, respectively $(P<$ 0.0001). CON-GR farms were 5.1 times less likely than ORG farms to test water for nitrates $(P=0.001)$ : $75 \%$ of CON-GR farms did not test, versus $37 \%$ of ORG farms. With respect to primary water source, no significant differences were found in surface water usage. More CON-GR farms used municipal water compared with ORG farms $(\mathrm{OR}=11.9, P=0.020)$.

Additions and Replacement Group. A larger percentage of CON-GR farms (14\%) accepted new preweaned heifers into their herds relative to $2 \%$ of ORG farms $(\mathrm{OR}=7.5, P=0.018)$. A larger percentage of ORG farms accepted new bulls (27\% compared with $11 \%$ of CON-NG farms, $\mathrm{OR}=3.8, P=0.009)$. The source of entering animals (single vs. multiple farms) did not differ between the 3 herd types.

\section{Supplementary Analysis: Johne's Disease Testing and Management}

Results for Johne's disease testing and management variables are shown in Appendix Table A1. In summary, well over half of producers for each production type reported a history of Johne's disease testing. Although the overall level of testing for Johne's disease was not significantly different, ORG farms were more likely to test the bulk tank milk supply.

\section{Compound Risk Factors}

All 2-level compound risk factors were evaluated, and any significant odds ratios from these logistic regressions are presented in Table 5. Organic herds were most susceptible to synergism of risk, with inferior performance to CON-NG herds with respect to all significantly different compound risk factors. Compared with CON-NG farms, ORG farms allowing $\geq 6 \mathrm{~h}$ of contact between the calf and the dam were 17.5 times less likely to have a dedicated calving area, 35.8 times more likely to allow sick or lactating cows into the calving area, and 11.2 times less likely to provide footbaths to periparturient 
Table 1. Assigned risk scores for the overall risk assessment

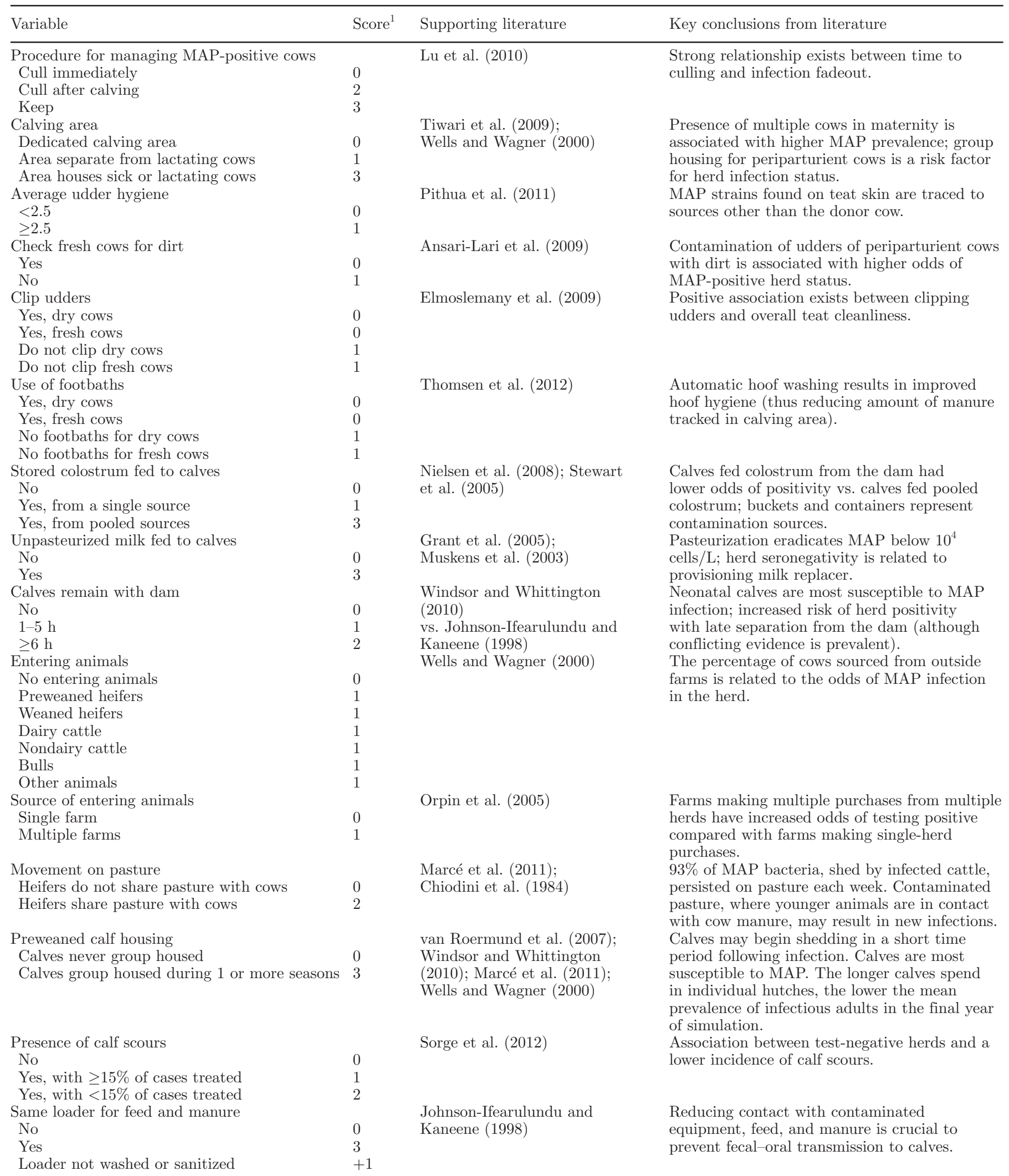


Table 1 (Continued). Assigned risk scores for the overall risk assessment

\begin{tabular}{llll}
\hline Variable & Score $^{1}$ & Supporting literature & Key conclusions from literature \\
\hline Spreading manure & & Obasanjo et al. (1997) & $\begin{array}{l}\text { Spreading manure and harvesting resulting } \\
\text { forage are associated with prevalence risk of } \\
\text { No }\end{array}$ \\
$\begin{array}{l}\text { infection. } \\
\text { Yes }\end{array}$ & 1 & & Surface water may be significant reservoir for \\
Water source & 0 & Whittington et al. (2005); & MAP infection. MAP may enter surface water \\
$\begin{array}{l}\text { Municipal or well water } \\
\text { Surface water }\end{array}$ & 2 & & as runoff from MAP-contaminated pastures. \\
\hline
\end{tabular}

${ }^{1}$ Practices that do not contribute to within-herd Mycobacterium avium ssp. paratuberculosis (MAP) proliferation or its introduction into the herd receive a score of 0 . Low, medium, and high risks are assigned 1,2, or 3, respectively. A score of 3 is given to practices with a direct relationship to the spread of MAP and a strong likelihood of occurrence given the presence of MAP.

cows. Compared with CON-NG farms, ORG farms allowing calves to nurse colostrum were 13.0 times more likely to have a poor average udder hygiene $(\geq 2.5), 6.3$ times less likely to clip the udders of fresh cows, and 43.7 times more likely to allow sick or lactating cows into the calving area.

Organic farms not performing bulk tank testing were 2.4 times more likely to feed unpasteurized waste milk and 3.4 times more likely to feed unpasteurized whole milk compared with CON-NG farms. One significant difference was found between the CON subtypes: farms spreading manure on pasture and accepting any entering animals were 4.1 times more likely to be CON-GR compared with CON-NG.

\section{DISCUSSION}

\section{Study Discussion}

Via an overall risk assessment analysis, we evaluated risk factors and common management decisions

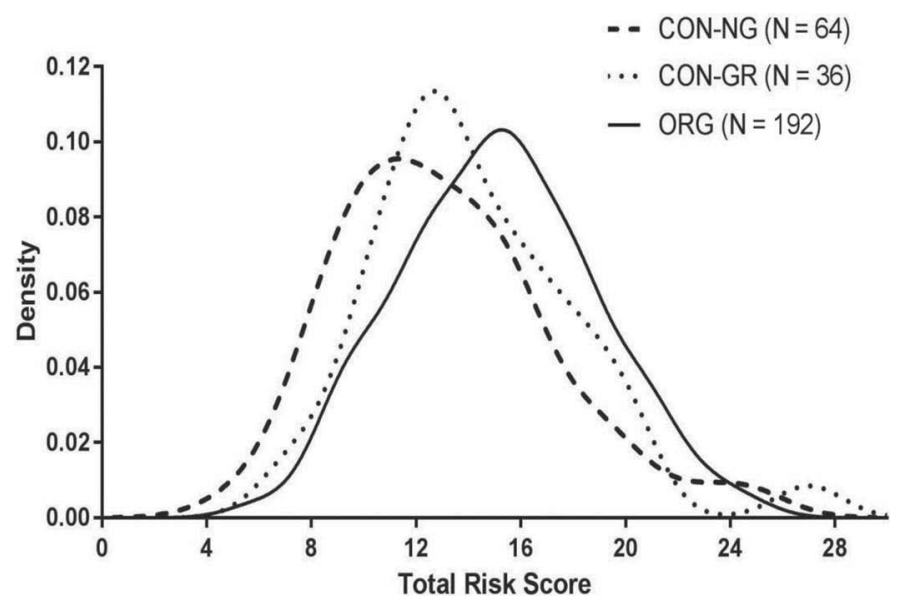

Figure 1. Overall risk assessment shown as a density plot depicting the relationship between production type (CON-GR, CON-NG, and ORG) and total risk score. Total risk score is shown on the $\mathrm{x}$-axis, and density of values on the $\mathrm{y}$-axis. The 3 curves estimate the density for each production type. $\mathrm{CON}-\mathrm{NG}=$ conventional nongrazing; CON-GR $=$ conventional grazing; ORG $=$ organic. and compared the overall level of risk for new cow-level MAP infections between 3 dairy production types. The risks were quantified according to literature on the pathobiology of MAP infection and modes of transmission. Organic herds demonstrated a significantly higher burden of risk than did both conventional grazing and nongrazing herds (see Figure 1). The overall risk assessment is based upon an amalgamation of individual, differentially important management choices; thus, we may refine our understanding of the increased risk for organic herds by homing in on categories contributing to the overall score and then on individual risk factors. As apparent in Figure 2, the calving area was a main area in which organic farms demonstrated an increased risk, in addition to preweaned calf management. In both categories, organic herds displayed higher risk scores compared with both conventional subgroups. No significant difference was found in the introduction risk between the production types; therefore, the focus of control strategies for organic farms may be refined to mitigating within-herd transmission, specifically for young calves.

According to the VBJDCP, management decisions in the calving area have the potential to accrue the highest level of risk because of the heightened susceptibility of calves to MAP infections (see Lombard, 2011). Based on consideration of individual management factors, organic farms tended to be less rigorous regarding the hygiene of periparturient cows. Specifically, organic farms exhibited a decreased likelihood of providing footbaths to dry and fresh cows (compared with nongrazing herds) and a decreased likelihood of clipping udders of fresh cows (compared with conventional grazing herds). Published evidence suggests that automatic washing of hooves results in improved hoof hygiene (Thomsen et al., 2012). The use of footbaths may therefore reduce the amount of manure tracked into the calving area by close-up animals. Similarly, udder cleanliness is an important management objective to reduce calf contact with cow manure; udders are recurrently contaminated with manure from other animals and from the environment (McAloon et al., 2015), and researchers have noted 
a positive association between udder clipping and teat cleanliness (Elmoslemany et al., 2009). Indeed, more than $80 \%$ of MAP from colostrum and teat-skin tests was previously traced to sources distinct from the donor cow (Pithua et al., 2011), highlighting the importance of teat skin cleanliness during the colostrum period, particularly for herds permitting suckling postpartum. Organic farms in our study more often allowed the calf to nurse, and likewise, a higher number of organic farms permitted 6 or more hours of contact between cow and calf. The VBJDCP recommends immediate separation of the calf from the dam and prevention of nursing, with calves remaining in the maternity pen for more than $6 \mathrm{~h}$ receiving the highest risk score.
Organic farms demonstrated increased risks in the preweaned calf group as well (as shown in Figure 2), with a greater tendency to provide unpasteurized whole milk to calves and to group-house calves (compared with farm with conventional grazing herds). Wells and Wagner (2000) determined that group-housing for preweaned calves is associated with an increased risk of MAP-positive herd status, and Tiwari et al. (2009) concluded that group-housing for preweaned calves, at least during the winter, was positively associated with the number of MAP seropositive cows. These findings substantiate calf-to-calf contact as a source of MAP transmission, though this parameter is not included as a risk factor in the VBJDCP. Additional evidence is de-

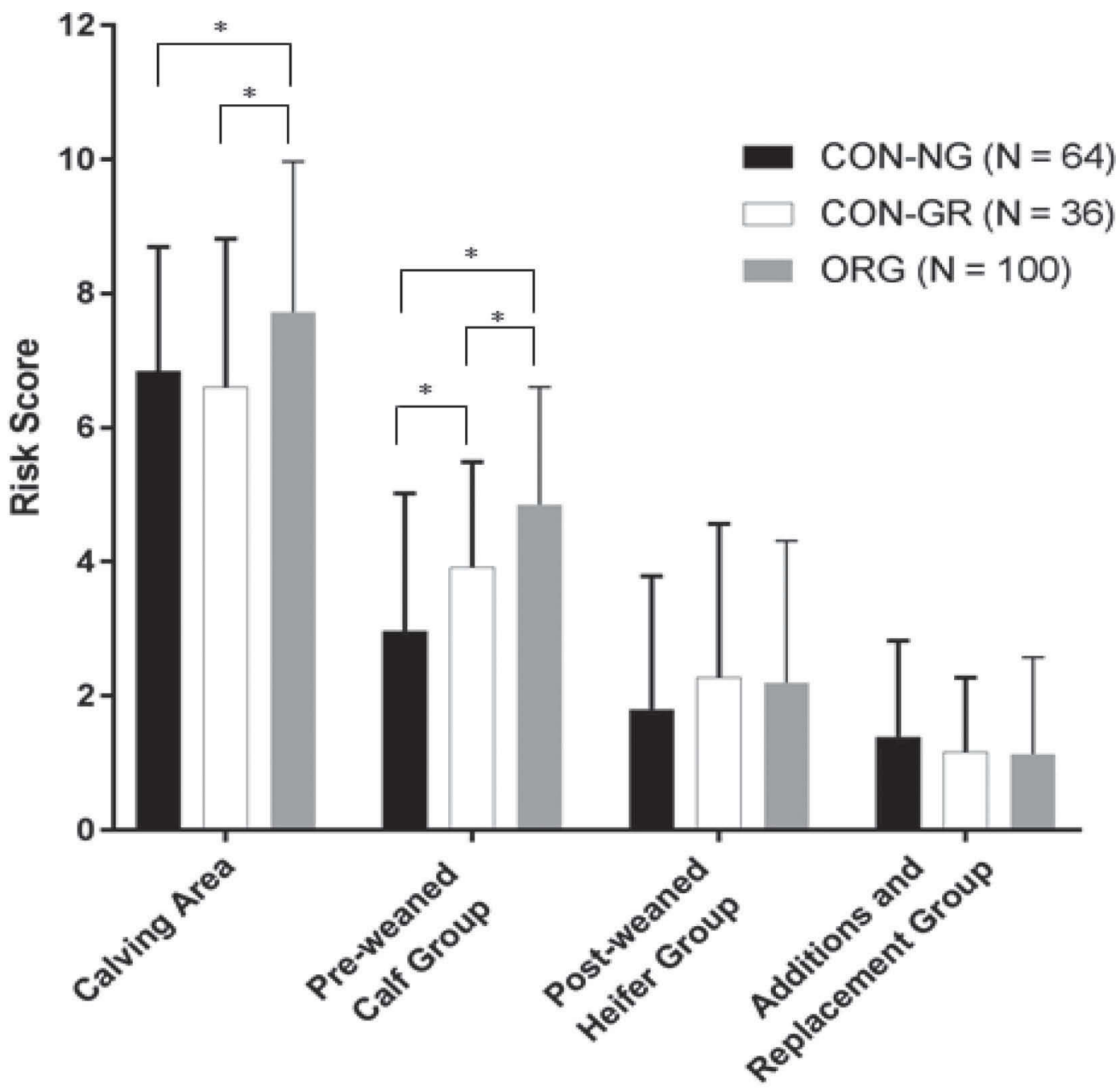

Categories of Risk

Figure 2. Overall risk assessment stratified by risk category. The individual risk categories (calving area, preweaned calf group, postweaned heifer group, and additions and replacement group) are shown on the x-axis. The average risk score for each grazing type in each risk category is presented. Significant differences $(P<0.05)$ between the production types are marked with asterisks. Error bars represent 1 SD. 
rived from the observation of horizontal MAP transmission in a group of calves (van Roermund et al., 2007). Because of the brief interval between infection and fecal shedding, the transmission risk between calves has been hypothesized to be intensified in a group-housing system (Mortier et al., 2014). The performance of organic herds in the overall risk assessment reflects the sum of these aforementioned management decisions.

Several parameters for which conventional farms had an inferior performance relative to organic herds are worth noting, although these individual factors were not prominent enough to affect the outcome of the overall risk assessment. First, $75 \%$ of conventional-grazing farms did not test their water sources for nitrates, whereas significantly more organic farms conducted nitrate testing. Nitrate pollution of surface water on farms may be indicative of fertilizer runoff (see Singh and Sekhon, 1979). Because manure ingestion by young animals is the primary means of MAP transmission (Doré et al., 2012), testing water for nitrates and taking subsequent actions to reduce manure pollution in the case of high nitrate values may be important control measures. However, this practice seems important primarily for farms using surface water as a main source.

Second, conventional farms did not outperform organic farms when it came to allowing certain groups of animals into the herd. Wells and Wagner (2000) confirmed that the percentage of cows sourced from outside farms was related to the odds of MAP-positive herd status, and Tiwari et al. (2009) found that increased MAP seroprevalence was related to the purchase of heifers during the previous year. Although organic farms purchased more bulls from outside sources, conventional-grazing farms were more likely to purchase preweaned heifers and nongrazing farms were more likely to purchase weaned heifers. No difference was found between the production types in the percentage of herds sourcing animals from multiple farms.

Finally, it is important to consider that several of the calving area risk factors contributing to the heightened risk for organic herds may not present an increased risk if executed alone. For example, although official MAP programs recommend immediate cow-calf separation, little empirical evidence exists to suggest that this practice leads to a demonstrable reduction in MAP infections. McAloon et al. (2015) asserted that empirical evidence supporting prompt calf removal as a preventative measure was relatively weak. Indeed, Wells and Wagner (2000) and Johnson-Ifearulundu and Kaneene (1998) reported no significant increase in MAP positivity when the calf was permitted to remain with the dam for an extended period. Another related

Table 2. Calving area management: Results are presented for the main predictor of interest, production type, with adjustments for herd size and state

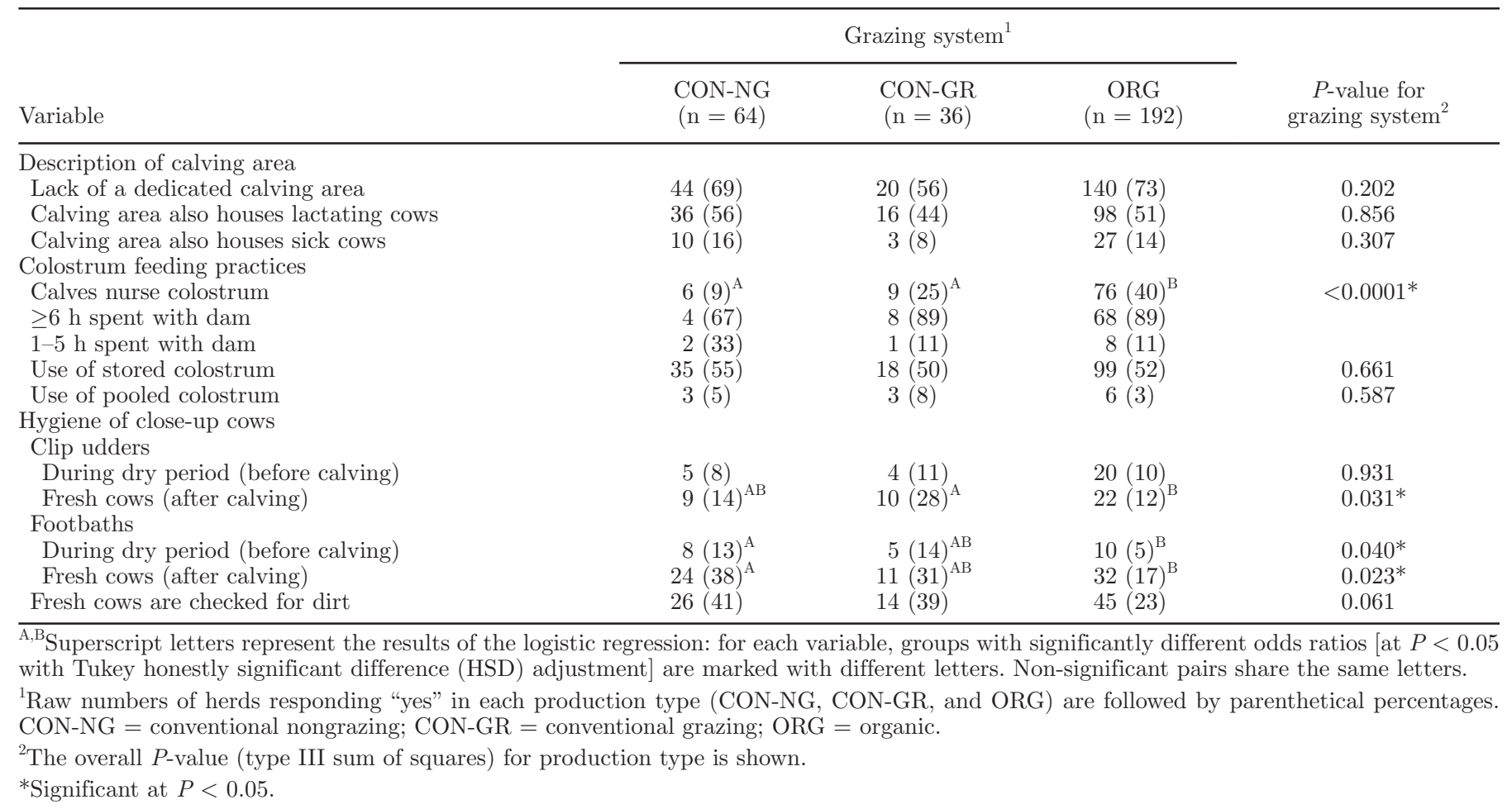


Table 3. Preweaned calf group and postweaned heifer group: Results are presented for the main predictor of interest, production type, with adjustments for herd size and state

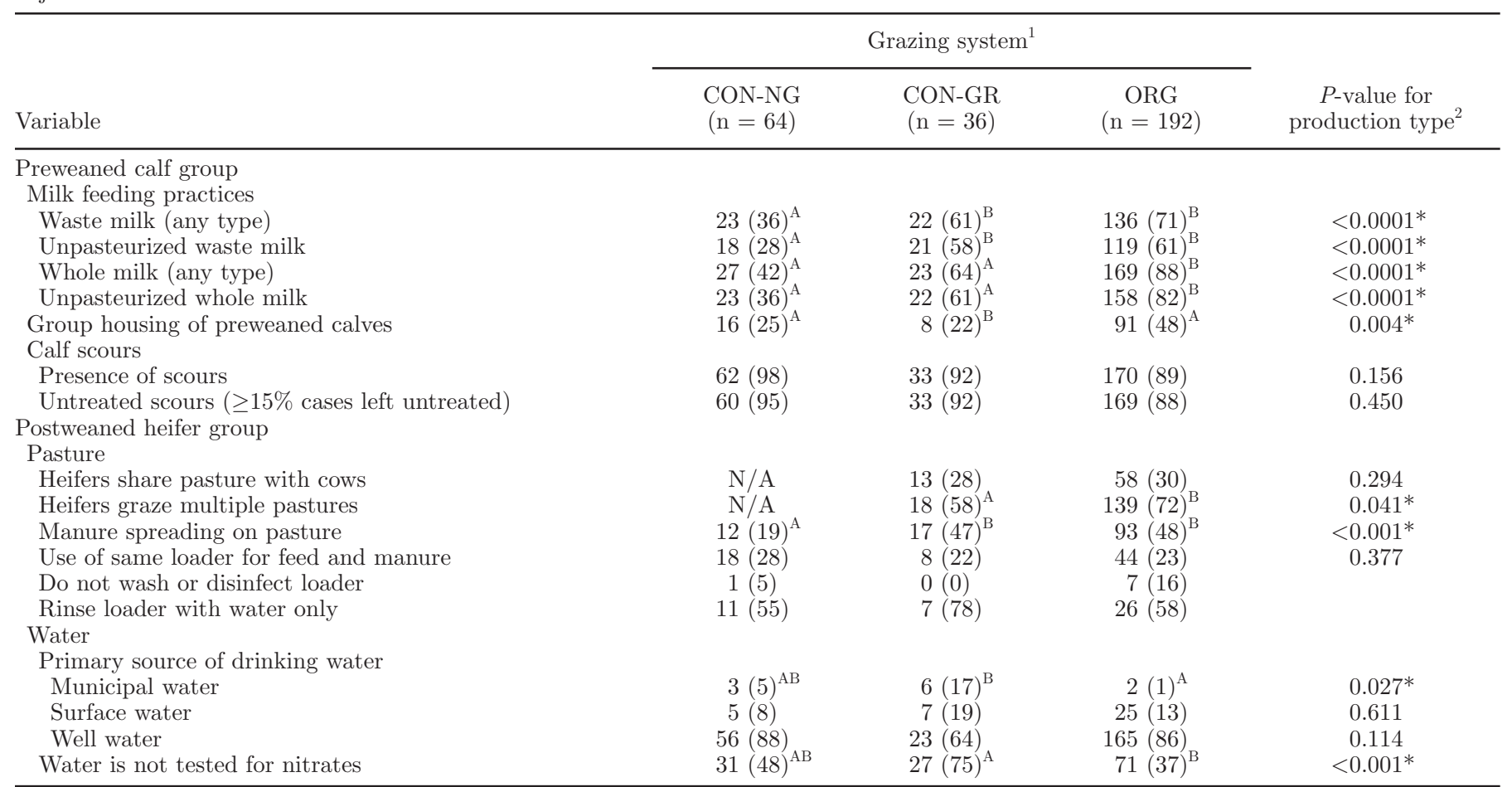

$\overline{\mathrm{A}, \mathrm{B}}$ Superscript letters represent the results of the logistic regression: for each variable, groups with significantly different odds ratios [at $P<$ 0.05 with Tukey honestly significant difference (HSD) adjustment] are marked with different letters. Nonsignificant pairs share the same letters. ${ }^{1}$ Raw numbers of herds responding "yes" in each production type (CON-NG, CON-GR, and ORG) are followed by parenthetical percentages. $\mathrm{CON}-\mathrm{NG}=$ conventional nongrazing; CON-GR = conventional grazing; ORG = organic.

${ }^{2}$ The overall $P$-value (type III sum of squares) for production type is shown.

*Significant at $P<0.05$.

Table 4. Additions and replacement group: Results are presented for the main predictor of interest, production type, with adjustments for herd size and state

\begin{tabular}{|c|c|c|c|c|}
\hline Variable & \multicolumn{3}{|c|}{ Grazing system $^{1}$} & $\begin{array}{c}P \text {-value for } \\
\text { grazing system }\end{array}$ \\
\hline Preweaned heifers & $2(3)^{\mathrm{AB}}$ & $5(14)^{\mathrm{B}}$ & $4(2)^{\mathrm{A}}$ & $0.020^{*}$ \\
\hline Weaned heifers & $17(27)^{\mathrm{A}}$ & $9(25)^{\mathrm{AB}}$ & $22(12)^{\mathrm{B}}$ & $0.031^{*}$ \\
\hline Dairy cows & $11(17)$ & $6(17)$ & $18(9)$ & 0.115 \\
\hline Any entering animal & $28(44)$ & $21(58)$ & $75(39)$ & 0.122 \\
\hline Source of entering animals (multiple farms vs. single farm) & $5(16)$ & $3(17)$ & $17(21)$ & 0.571 \\
\hline No. of entering animals ${ }^{3}$ & 7.69 & 5.73 & 8.72 & 0.898 \\
\hline
\end{tabular}

$\overline{\mathrm{A}, \mathrm{B}}$ Superscript letters represent the results of the logistic regression: for each variable, groups with significantly different odds ratios [at $P<$ 0.05 with Tukey honestly significant difference (HSD) adjustment] are marked with different letters. Nonsignificant pairs share the same letters. ${ }^{1}$ Raw numbers of herds responding "yes" in each production type (CON-NG, CON-GR, and ORG) are followed by parenthetical percentages. $\mathrm{CON}-\mathrm{NG}=$ conventional nongrazing; $\mathrm{CON}-\mathrm{GR}=$ conventional grazing; $\mathrm{ORG}=$ organic.

${ }^{2}$ The overall $P$-value (type III sum of squares) for production type is shown.

${ }^{3}$ Assessed using linear (rather than logistic) regression; LSM are provided.

*Significant at $P<0.05$. 
Table 5. Compound risk factors: The odds ratios for significant $(P<0.05)$ compound risk factors from the logistic regression analyses are presented

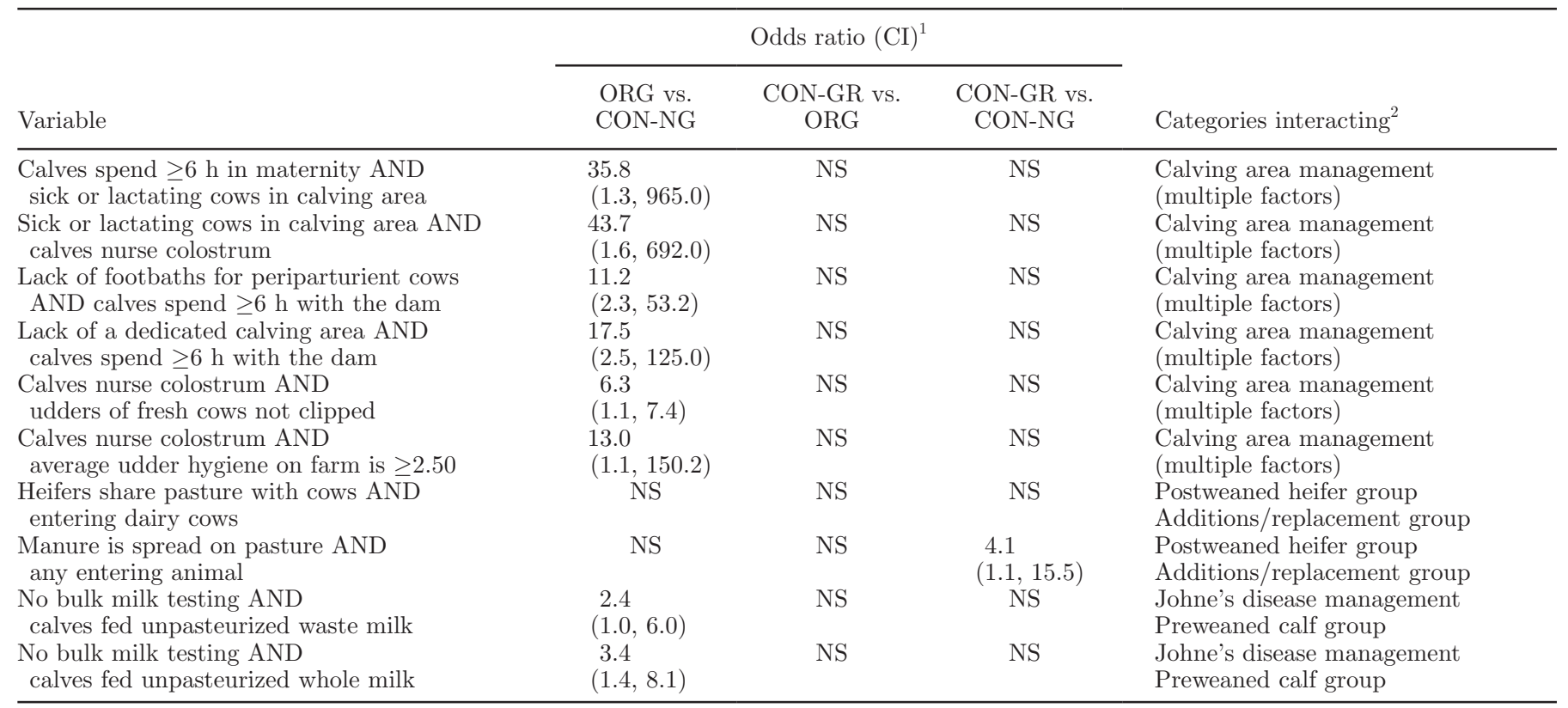

${ }^{1}$ Confidence intervals (in parentheses) reflect a Tukey honestly significant difference (HSD) correction. Only those compound risk factors with at least 1 significant odds ratio are shown. $\mathrm{NS}=$ nonsignificant odds ratios; $\mathrm{CON}-\mathrm{NG}=$ conventional nongrazing; CON-GR $=$ conventional grazing; ORG $=$ organic.

${ }^{2}$ Categories of risk that are interacting for each variable.

practice involves permitting the calf to nurse. In one study (Stewart et al., 2005), bacterial contamination resulted from milking colostrum into a bucket before transfer to a sterile sampling container. In contrast, bacterial counts from directly stripped colostrum were comparatively low. Stewart et al. (2005) concluded that harvesting colostrum was the stage most prone to contamination due to a soiled udder, milking machine, or improperly sanitized bucket. The means of storage and number of storage containers could affect colostrum quality, and pooling colostrum could increase the risk of exposure to pathogens (Godden, 2008). High bacterial counts may be indicative of fecal contamination. Therefore, the act of nursing the dam may not represent an increased risk of MAP transmission compared with other means of obtaining colostrum.

Nevertheless, the calving area is ripe for the synergism of risk factors, particularly because of increased susceptibility of neonatal calves. Goodger et al. (1996) present a compelling case for "multifactorial" risks in MAP transmission by evaluating cumulative risk scores against herd prevalence. Care of newborn calves significantly interacted with several other categories, including manure handling and environmental conditions; thus, certain variables appear to have a different relationship to prevalence when combined. Moreover, validation is provided to the notion that newborn calf care is particularly important in reference to risk synergy. From the current data, organic farms do not appear to take precautions to avoid the synergistic relationship of risk factors. Because nursing and prolonged dam-calf contact is more often permitted on organic farms, hygiene of fresh cows is paramount. However, organic farms were 6 times more likely than farms with conventional nongrazing herds to allow calves to nurse without clipping the udders of periparturient cows. Farms with poor udder hygiene (average score $\geq$ 2.50) allowing the calf to nurse from the dam were 13 times more likely to be organic rather than nongrazing. Organic management was also significantly less likely than conventional nongrazing farms to provide footbaths while allowing extended dam-calf contact $(\geq 6$ h). As previously mentioned, footbaths are important in maintaining hoof hygiene (Thomsen et al., 2012) and a calving area free of manure.

Tiwari et al. (2009) concluded that the presence of multiple cows in the maternity area was associated with a higher MAP seroprevalence, and Wells and Wagner (2000) asserted that group housing for periparturient cows was a main risk factor for MAP-positive herd status. Compared with farms with conventional nongrazing herds, organic dairy farms were significantly 
more likely to lack a dedicated calving area while simultaneously allowing calves to spend 6 or more hours in that environment. Moreover, organic farms more often permitted calf nursing while allowing sick animals or other lactating cows to be present in the calving area.

In a study by Muskens et al. (2003), providing milk replacer to calves was related to herd seronegativity in a univariable analysis; thus, routine MAP testing of bulk milk to ensure its negativity could ameliorate milk-source transmission risk. Pasteurization may also be used as a safeguarding tool for bulk milk when MAP concentrations are below $10^{4}$ cells/L (Grant et al., 2005). The increased level of bulk milk testing in organic herds (see Table A1 in Appendix) may be in response to the more common practice of feeding unpasteurized whole milk to calves. Indeed, the absence of a commercially available organic milk replacer (Stiglbauer et al., 2013) is likely a contributing factor to an increased MAP infection risk and may prompt organic farms to increase MAP testing of their milk. However, organic farms were still over 3 times more likely to feed calves a combination of unpasteurized, untested whole milk compared with farms with nongrazing herds.

It is important to note that certain management practices more commonly executed by organic farms may be beneficial from an animal welfare standpoint, such as contact between a dam and her calf and group housing for calves. In the present study, approximately $40 \%$ of organic farms permitted calves to nurse. Consumers purchasing organic products may envision this type of practice because they have expressed a preference for more natural calf rearing (Vasseur et al., 2010). Although some conflicting evidence exists (see McGuirk and Collins, 2004), cow and calf contact and nursing have been shown to have health, welfare, and production benefits. Bar-Peled et al. (1997) concluded that heifer calves permitted to nurse had higher average daily gains than bucket-fed calves and showed a higher conception rate and milk production later in life. The presence of the dam may even increase calf immunoglobulin absorption (Selmann et al., 1970; Stott et al., 1979). Additionally, welfare benefits seem to exist for group-housed calves because calves isolated at birth have demonstrated increased behavioral and physiological indicators of stress (Creel and Albright, 1988) and have shown impaired performance on cognitive tests (Gaillard et al., 2014). The MAP transmission risk for group-housed calves may be mitigated if the probability of MAP transmission to calves in the calving area is diminished. The trends in our data suggest that organic farms would do well to improve hygiene in the calving area to better accommodate such practices. Initiatives may include clipping and cleaning udders of periparturient cows, providing footbaths, and increasing overall udder hygiene. A dedicated calving area with minimal manure contamination appears to be of great importance in keeping the risk of MAP spread to a minimum, particularly if calves spend an extended period within this area.

\section{Study Limitations and Future Directions}

Differences in general management practices on conventional-grazing, nongrazing, and organic farms are presented in Stiglbauer et al. (2013), with a small degree of overlap with the present study. To present a complete picture of the risk factors, reanalyzing several variables was necessary; however, Stiglbauer et al. (2013) focused on general management, so implications of management practices on the spread of MAP were not discussed.

Conclusions regarding organic management practices in the United States are difficult to extend to other countries because practices for organic management differ substantially between countries (Stiglbauer et al., 2013). Future work will be necessary to uncover disparities in Johne's disease risk between production types in other countries where the standards for organic production vary. For example, in most EU countries, calf nursing is advocated by some organic producers but is not compulsory. However, nursing during at least a portion of the colostrum period is a requisite for organic dairy production in Sweden, Norway, and Denmark (see Johnsen et al., 2015). Although Johne's disease appears to be well controlled in Norway, no country has published enough evidence to claim zero or near-zero MAP prevalence (Nielsen and Toft, 2009). Initially, questionnaires similar to the one employed in our study could be used to glean an understanding of country- or region-specific organic management practices and MAP risk factors. Intervention studies aimed at reducing risk on organic farms could subsequently be designed based upon common organic management practices in a given area. Better prevalence and incidence estimates are necessary in some countries (Nielsen et al., 2000; Nielsen and Toft, 2009), in addition to a breakdown of prevalence on organic versus conventional farms.

Some evidence indicates that participation of organic herds in Johne's disease control programs is diminished relative to participation of conventional herds. This situation is particularly concerning in countries where the herd-level prevalence is high. In the Netherlands, where overall herd-level prevalence ranges from 31 to $71 \%$ (Muskens et al., 2000), few organic farmers have chosen to participate in the voluntary national prevention program (Kijlstra and Eijck, 2009). In the United 
States as well (70.4\% prevalence, Lombard et al., 2013), some evidence shows that fewer organic herds choose to participate in control programs (Beaver et al., 2016). This resistance may in part be due to the consistent recommendations of such programs to avoid practices seen as important to the organic dairy farmer. Management initiatives could therefore be tailored specifically to organic herds, with the goal of better accommodating rather than eliminating such practices, and safeguarding against synergism of risk factors.

\section{CONCLUSIONS}

In an overall risk assessment, organic herds demonstrated significantly higher risk of MAP transmission than both conventional grazing and nongrazing herds. Decisions regarding postweaned heifer management and purchase of additional animals seem to be comparably executed across the 3 production types; thus, the heightened risk for organic herds appears to be primarily due to management in the calving area and subsequent housing of preweaned calves. However, certain management practices traditionally cited as risk factors (e.g., prolonged cow-calf contact and nursing) lack a supporting body of empirical evidence to associate them with increased MAP prevalence. Such practices may even be beneficial for animal welfare. Nonetheless, these practices have the potential to interact with other management decisions and act synergistically on the risk of MAP transmission. An increased awareness of hygiene in the calving area is therefore necessary for farms electing to permit cow-calf contact, nursing, and subsequent group housing of calves. The organic farms in our study did not appear to take these extra precautions with regard to hygiene; consequently, increased vigilance is recommended to mitigate an increased risk.

\section{ACKNOWLEDGMENTS}

Many thanks to members of the Schukken Laboratory at Cornell University: Anja Sipka, Brianna Pomeroy, and Suzanne Klaessig for fruitful discussion and assistance with GraphPad software. This study was supported by the USDA-NIFA Integrated Organic Program, grant no. 2008-51106-19463, "Impact of Organic Management on Dairy Animal Health and Well-Being."

\section{REFERENCES}

Ansari-Lari, M., M. Haghkhah, A. Bahramy, and A. M. N. Baheran. 2009. Risk factors for Mycobacterium avium subspecies paratuberculosis in Fars Province (southern Iran) dairy herds. Trop. Anim. Health Prod. 41:553-557.
Bar-Peled, U., B. Robinzon, E. Maltz, H. Tagari, Y. Folman, I. Bruckental, H. Voet, H. Gacitua, and A. Lehrer. 1997. Increased weight gain and effects on production parameters of Holstein heifer calves that were allowed to suckle from birth to six weeks of age. J. Dairy Sci. 80:2523-2528.

Beaver, A., C. Cazer, P. Ruegg, Y. Gröhn, and Y. Schukken. 2016. Implications of PCR and ELISA results on the routes of bulk-tank contamination with Mycobacterium avium ssp. paratuberculosis. J. Dairy Sci. 99:1391-1405.

Bergman, M. A., R. M. Richert, K. M. Cicconi-Hogan, M. J. Gamroth, Y. H. Schukken, K. E. Stiglbauer, and P. L. Ruegg. 2014. Comparison of selected animal observations and management practices used to assess welfare of calves and adult dairy cows on organic and conventional dairy farms. J. Dairy Sci. 97:4269-4280.

Cazer, C. L., R. M. Mitchell, K. M. Cicconi-Hogan, M. Gamroth, R. M. Richert, P. L. Ruegg, and Y. H. Schukken. 2013. Associations between Mycobacterium avium ssp. paratuberculosis antibodies in bulk tank milk, season of sampling and protocols for managing infected cows. BMC Vet. Res. 9:234.

Chiodini, R. J., H. J. van Kruiningen, and R. S. Merkal. 1984. Ruminant paratuberculosis (Johne's disease): The current status and future prospects. Cornell Vet. 74:218-262.

Cicconi-Hogan, K. M., M. Gamroth, R. Richert, P. L. Ruegg, K. E. Stiglbauer, and Y. H. Schukken. 2013. Associations of risk factors with somatic cell count in bulk tank milk on organic and conventional dairy farms in the United States. J. Dairy Sci. 96:3689-3702.

Creel, S., and J. Albright. 1988. The effects of neonatal social isolation on the behavior and endocrine function of Holstein calves. Appl. Anim. Behav. Sci. 21:293-306.

Doré, E., J. Paré, G. Côté, S. Buczinski, O. Labrecque, J. Roy, and G. Fecteau. 2012. Risk factors associated with transmission of $\mathrm{Myco-}$ bacterium avium ssp. paratuberculosis to calves within dairy herd: A systematic review. J. Vet. Intern. Med. 26:32-45.

Elmoslemany, A. M., G. P. Keefe, I. R. Dohoo, and B. M. Jayarao. 2009. Risk factors for bacteriological quality of bulk tank milk in Prince Edward Island dairy herds. Part 1: Overall risk factors. J. Dairy Sci. 92:2634-2643.

Feller, M., K. Huwiler, R. Stephan, E. Altpeter, A. Shang, H. Furrer, G. E. Pfyffer, T. Jemmi, A. Baumgartner, and M. Egger. 2007. Mycobacterium avium subspecies paratuberculosis and Crohn's disease: A systematic review and meta-analysis. Lancet Infect. Dis. 7:607-613.

Gaillard, C., R. K. Meagher, M. A. von Keyserlingk, and D. M. Weary. 2014. Social housing improves dairy calves' performance in two cognitive tests. PLoS ONE 9:e90205.

Godden, S. 2008. Colostrum management for dairy calves. Vet. Clin. North Am. Food Anim. Pract. 24:19-39.

Goodger, W. J., M. T. Collins, K. V. Nordlund, C. Eisele, J. Pelletier, C. B. Thomas, and D. C. Sockett. 1996. Epidemiologic study of on-farm management practices associated with prevalence of $M y$ cobacterium paratuberculosis infections in dairy cattle. J. Am. Vet. Med. Assoc. 208:1877-1881.

Grant, I. R., A. G. Williams, M. T. Rowe, and D. D. Muir. 2005. Efficacy of various pasteurization time-temperature conditions in combination with homogenization on inactivation of Mycobacterium avium ssp. paratuberculosis in milk. Appl. Environ. Microbiol. 71:2853-2861.

Johnsen, J. F., A. M. de Passille, C. M. Mejdell, K. E. Bøe, A. M. Grøndahl, A. Beaver, J. Rushen, and D. M. Weary. 2015. The effect of nursing on the cow-calf bond. Appl. Anim. Behav. Sci. 163:50-57.

Johnson-Ifearulundu, Y. J., and J. B. Kaneene. 1998. Managementrelated risk factors for $M$. paratuberculosis infection in Michigan, USA, dairy herds. Prev. Vet. Med. 37:41-54.

Kijlstra, A., and I. Eijck. 2006. Animal health in organic livestock production systems: A review. NJAS-Wageningen J. Life Sci. 54:77-94.

Lombard, J. E., I. A. Gardner, S. R. Jafarzadeh, C. P. Fossler, B. Harris, R. T. Capsel, B. A. Wagner, and W. O. Johnson. 2013. 
Herd-level prevalence of Mycobacterium avium subsp. paratuberculosis infection in United States dairy herds in 2007. Prev. Vet. Med. 108:234-238.

Lombard, J. E. 2011. Epidemiology and economics of paratuberculosis. Vet. Clin. North Am. Food Anim. Pract. 27:525-535.

Lu, Z., Y. H. Schukken, R. L. Smith, and Y. T. Grohn. 2010. Stochastic simulations of a multi-group compartmental model for Johne's disease on US dairy herds with test-based culling intervention. J. Theor. Biol. 264:1190-1201.

Manning, E. J., and M. T. Collins. 2001. Mycobacterium avium ssp. paratuberculosis: Pathogen, pathogenesis and diagnosis. Rev. Sci. Tech. 20:133-150.

Marcé, C., P. Ezanno, H. Seegers, D. Pfeiffer, and C. Fourichon. 2011. Within-herd contact structure and transmission of Mycobacterium avium subspecies paratuberculosis in a persistently infected dairy cattle herd. Prev. Vet. Med. 100:116-125.

McAloon, C. G., P. Whyte, S. J. More, L. O'Grady, and M. L Doherty. 2015. Development of a HACCP-based approach to control paratuberculosis in infected Irish dairy herds. Prev. Vet. Med. 120:152-161.

McGuirk, S. M., and M. Collins. 2004. Managing the production, storage, and delivery of colostrum. Vet. Clin. North Am. Food Anim. Pract. 20:593-603.

Mortensen, H., S. S. Nielsen, and P. Berg. 2004. Genetic variation and heritability of the antibody response to Mycobacterium avium subspecies paratuberculosis in Danish Holstein cows. J. Dairy Sci. 87:2108-2113.

Mortier, R. A., H. W. Barkema, K. Orsel, R. Wolf, and J. De Buck. 2014. Shedding patterns of dairy calves experimentally infected with Mycobacterium avium subspecies paratuberculosis. Vet. Res. 45:71.

Muskens, J., H. Barkema, E. Russchen, K. Van Maanen, Y. Schukken, and D. Bakker. 2000. Prevalence and regional distribution of paratuberculosis in dairy herds in the Netherlands. Vet. Microbiol. $77: 253-261$.

Muskens, J., A. Elbers, H. van Weering, and J. Noordhuizen. 2003. Herd management practices associated with paratuberculosis seroprevalence in Dutch dairy herds. J. Vet. Med. B. Infect. Dis. Wet. Public Health 50:372-377.

Nielsen, S. S., H. Bjerre, and N. Toft. 2008. Colostrum and milk as risk factors for infection with Mycobacterium avium subspecies paratuberculosis in dairy cattle. J. Dairy Sci. 91:4610-4615.

Nielsen, S. S., S. M. Thamsborg, H. Houe, and V. Bitsch. 2000. Bulktank milk ELISA antibodies for estimating the prevalence of paratuberculosis in Danish dairy herds. Prev. Vet. Med. 44:1-7.

Nielsen, S. S., and N. Toft. 2009. A review of prevalences of paratuberculosis in farmed animals in Europe. Prev. Vet. Med. 88:1-14.

Obasanjo, I. O., Y. Gröhn, and H. O. Mohammed. 1997. Farm factors associated with the presence of Mycobacterium paratuberculosis infection in dairy herds on the New York state paratuberculosis control program. Prev. Vet. Med. 32:243-251.

Organic Trade Association. 2016. U.S. Organic: State of the industry. Accessed Apr. 2, 2016. http://ota.com/sites/default/files/ indexed_files/OTA_StateofIndustry_2016.pdf

Orpin, P., S. Duthie, and D. H. Grove-White. 2005. The use of targeted sampling and risk factor analysis to investigate the presence of Johne's disease in dairy herds. Cattle Pract. 13:219-225.

Ott, S. L., S. J. Wells, and B. A. Wagner. 1999. Herd-level economic losses associated with Johne's disease on US dairy operations. Prev. Vet. Med. 40:179-192.

Pickup, R. W., G. Rhodes, T. J. Bull, S. Arnott, K. Sidi-Boumedine, M. Hurley, and J. Hermon-Taylor. 2006. Mycobacterium avium ssp. paratuberculosis in lake catchments, in river water abstracted for domestic use, and in effluent from domestic sewage treatment works: Diverse opportunities for environmental cycling and human exposure. Appl. Environ. Microbiol. 72:4067-4077.

Pieper, L., U. Sorge, A. Godkin, T. DeVries, K. Lissemore, and D. Kelton. 2014. Management practices and their potential influence on Johne's disease transmission on Canadian organic dairy farms-A conceptual analysis. Sustainability. 6:8237-8261.
Pithua, P., S. J. Wells, and S. M. Godden. 2011. Evaluation of the association between fecal excretion of Mycobacterium avium subsp paratuberculosis and detection in colostrum and on teat skin surfaces of dairy cows. J. Am. Vet. Med. Assoc. 238:94-100. J. Am. Vet. Med. Assoc. 238(11):1440 (Note: Stabel, Judith R [added]).

Richert, R. M., K. M. Cicconi, M. J. Gamroth, Y. H. Schukken, K. E. Stiglbauer, and P. L. Ruegg. 2013. Risk factors for clinical mastitis, ketosis, and pneumonia in dairy cattle on organic and small conventional farms in the United States. J. Dairy Sci. 96:4269-4285.

Schreiner, D. A., and P. L. Ruegg. 2003. Relationship between udder and leg hygiene scores and subclinical mastitis. J. Dairy Sci. $86: 3460-3465$

Selman, I. E., A. D. McEwan, and E. W. Fisher. 1970. Studies on natural suckling in cattle during the first eight hours post partum II. Behavioural studies (calves). Anim. Behav. 18:284-289.

Singh, B., and G. Sekhon. 1979. Nitrate pollution of groundwater from farm use of nitrogen fertilizers-A review. Agric. Environ. $4: 207-225$.

Slana, I., M. Liapi, M. Moravkova, A. Kralova, and I. Pavlik. 2009. Mycobacterium avium ssp. paratuberculosis in cow bulk tank milk in Cyprus detected by culture and quantitative IS900 and F57 real-time PCR. Prev. Vet. Med. 89:223-226.

Sorge, U. S., K. Lissemore, A. Godkin, J. Jansen, S. Hendrick, S. Wells, and D. F. Kelton. 2012. Risk factors for herds to test positive for Mycobacterium avium ssp. paratuberculosis-antibodies with a commercial milk enzyme-linked immunosorbent assay (ELISA) in Ontario and western Canada. Can. Vet. J. 53:963-970.

Stewart, S., S. Godden, R. Bey, P. Rapnicki, J. Fetrow, R. Farnsworth, M. Scanlon, Y. Arnold, L. Clow, and K. Mueller. 2005. Preventing bacterial contamination and proliferation during the harvest, storage, and feeding of fresh bovine colostrum. J. Dairy Sci. 88:25712578 .

Stiglbauer, K. E., K. M. Cicconi-Hogan, R. Richert, Y. H. Schukken, P. L. Ruegg, and M. Gamroth. 2013. Assessment of herd management on organic and conventional dairy farms in the United States. J. Dairy Sci. 96:1290-1300.

Stott, G. H., D. B. Marx, B. E. Menefee, and G. T. Nightengale. 1979. Colostral immunoglobulin transfer in calves. IV. Effect of suckling. J. Dairy Sci. 62:1908-1913.

Sweeney, R. W., R. H. Whitlock, and A. E. Rosenberger. 1992. Mycobacterium paratuberculosis cultured from milk and supramammary lymph nodes of infected asymptomatic cows. J. Clin. Microbiol. 30:166-171.

Thomsen, P. T., A. K. Ersbøll, and J. T. Sørensen. 2012. Short communication: Automatic washing of hooves can help control digital dermatitis in dairy cows. J. Dairy Sci. 95:7195-7199.

Tiwari, A., J. Vanleeuwen, I. Dohoo, G. Keefe, J. Haddad, H. Scott, and T. Whiting. 2009. Risk factors associated with Mycobacterium avium subspecies paratuberculosis seropositivity in Canadian dairy cows and herds. Prev. Vet. Med. 88:32-41.

van Roermund, H. J., D. Bakker, P. T. Willemsen, and M. C. de Jong 2007. Horizontal transmission of Mycobacterium avium subsp. paratuberculosis in cattle in an experimental setting: Calves can transmit the infection to other calves. Vet. Microbiol. 122:270-279.

van Weering, H., G. van Schaik, A. van der Meulen, M. Waal, P. Franken, and K. van Maanen. 2007. Diagnostic performance of the pourquier ELISA for detection of antibodies against Mycobacterium avium subspecies paratuberculosis in individual milk and bulk milk samples of dairy herds. Vet. Microbiol. 125:49-58.

Vasseur, E., F. Borderas, R. I. Cue, D. Lefebvre, D. Pellerin, J. Rushen, K. M. Wade, and A. M. de Passillé. 2010. A survey of dairy calf management practices in Canada that affect animal welfare. J. Dairy Sci. 93:1307-1315.

Wells, S. J., and B. A. Wagner. 2000. Herd-level risk factors for infection with Mycobacterium paratuberculosis in US dairies and association between familiarity of the herd manager with the disease or prior diagnosis of the disease in that herd and use of preventive measures. J. Am. Vet. Med. Assoc. 216:1450-1457. 
Whitlock, R. H., and C. Buergelt. 1996. Preclinical and clinical manifestations of paratuberculosis (including pathology). Vet. Clin. North Am. Food Anim. Pract. 12:345-356.

Whittington, R. J., I. B. Marsh, and L. A. Reddacliff. 2005. Survival of Mycobacterium avium ssp. paratuberculosis in dam water and sediment. Appl. Environ. Microbiol. 71:5304-5308.

Wilson, D. J., K. Rood, P. Biswas, and T. M. Byrem. 2010. Herd-level prevalence of Johne's disease in Utah and adjacent areas of the intermountain west as detected by a bulk-tank milk surveillance project. J. Dairy Sci. 93:5792-5797.

Windsor, P. A., and R. J. Whittington. 2010. Evidence for age susceptibility of cattle to Johne's disease. Vet. J. 184:37-44.

Zwald, A. G., P. L. Ruegg, J. B. Kaneene, L. D. Warnick, S. J. Wells, C. Fossler, and L. W. Halbert. 2004. Management practices and reported antimicrobial usage on conventional and organic dairy farms. J. Dairy Sci. 87:191-201.

\section{APPENDIX}

Table A1. Johne's disease testing and management: results are presented for the main predictor of interest, production type, with adjustments for herd size and state

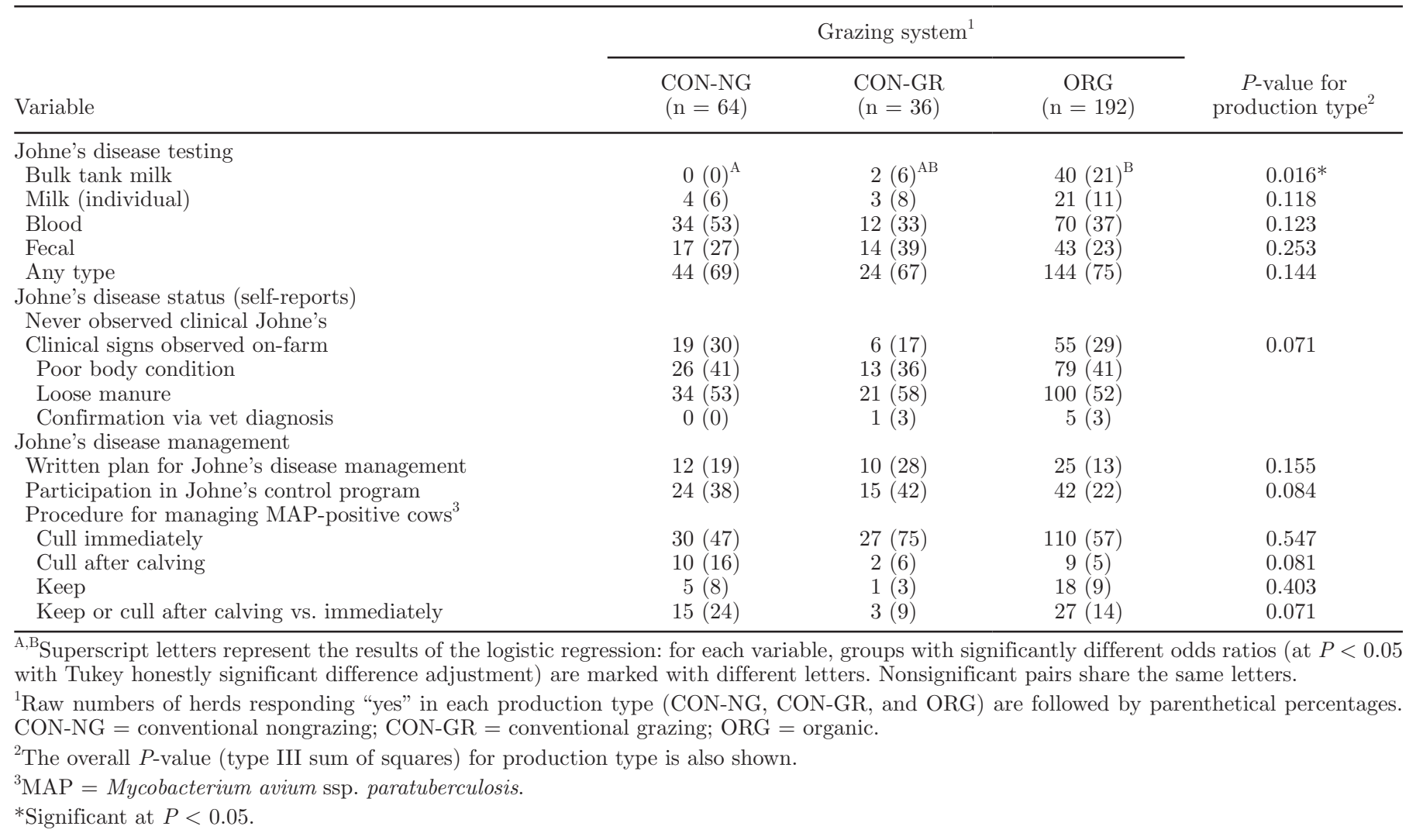

